\title{
The NHS and the financial storm: practical solutions with Jelonet dressing
}

\author{
Thomas F. E. Clarke • S. Haroon A. Shah • Saadia Syed
}

Received: 17 January 2011 / Accepted: 7 February 2011 /Published online: 1 March 2011

(C) Springer-Verlag 2011

Sir,

Jelonet is a sterile tulle gras paraffin gauze dressing widely known for its properties of low adherence, allowance for exudate passage and suitability for combination with use of other topical agents. These features have allowed its global use for burns, scalds, donor and recipient skin graft sites, skin loss wounds and leg ulcers [1].

In our daily practice, we have developed uses for the Jelonet enveloping paper. A major use of this is as a template for planning full-thickness skin grafts. The paper is placed over the host site with low adherence, and the impression from the wound gives an exact outline of the graft needed from the donor site.

The properties of low adherence extend its use as a foundation to place a harvested split-thickness skin graft for fenestration. This is often done on the theatre trolley or on the surface of a kidney dish. This could result in the potential for shearing of the epidermal or dermal layers of the graft.

Some of the paraffin that is impregnated into the Jelonet remains as a residue on the enveloping paper. This can be used on the donor site for split-thickness skin grafts as an alternative to other agents such as Vaseline [2]. This residue can also lubricate multifilament suture materials to encourage smooth and atraumatic passage through the tissues.

T. F. E. Clarke $\cdot$ S. H. A. Shah $\cdot$ S. Syed

Department of Plastic and Reconstructive Surgery,

Royal Preston Hospital,

Sharoe Green Lane,

Preston PR29HT, UK

T. F. E. Clarke $(\bowtie)$

68 Wellin Lane, Edwalton,

Nottingham NG124AH, UK

e-mail: Tomclarke3@googlemail.com
Surgical procedures at anatomical sites where hair is present can be challenging, for example, during pinnaplasty or scalp surgery. Hair can often obstruct the operating field, making preparation, draping and the procedure itself difficult. The paraffin residue on Jelonet's enveloping paper can be very helpful in sticking back hair and thus reducing this unnecessary complication [3].

Financial restraints have never been more prevalent than today. Whereas, in the past, they may not have had such an impact on the choice and use of dressings in theatre, today this is not the case [4]. By employing the techniques described above, the uses of the Jelonet dressing can be more far reaching and reduce the need for additional materials in the operating room.

We look forward to and hope this article will stimulate other departments to find innovative methods to improve cost efficiency and also reduce waste.

Conflict of interests None.

Funding None.

\section{References}

1. Jelonet dressing. At http://wound.smith-nephew.com/uk/Product. asp? NodeId $=738$ Access Nov. 2, 2010

2. Chen J, Su GL, Li Q, Tang ZJ, Su SJ, Shi JW (2009) Effect of different dressing materials in various combinations on wound microenvironment of donor site in burn patients. Zhonghua Shao Shang Za Zhi 25(3):218-221

3. Wain RA, Shah SH (2011) Practical perioperative pinnaplasty preparation. Aesthetic Plastic Surgery (in press)

4. Mahajan AL, Riordan CL, Regan PJ (2003) Why have paper when you can have silk? Plast Reconstr Surg 111(5):1759-1760 